\title{
Vitamin a and iron deficiency in pregnant women, lactating mothers and their infants in Adamawa State, Nigeria: a prospective cohort study.
}

\author{
Jennifer A. Tyndall ${ }^{1}, \mathrm{PhD}$, Valentine Okoye ${ }^{1}$, Frances Elumelu ${ }^{1}$, Aishatu Dahiru ${ }^{1}$ \& \\ Hammad Bapetel Pariya ${ }^{2}$, MD. \\ ${ }^{1}$ Department of Natural \& Environmental Sciences, American University of Nigeria, Yola, \\ Adamawa State. \\ 2 Department of Primary Care, Ministry of Health, Adamawa State. \\ Email Address of corresponding author = tyndalljen@yahoo.com
}

\begin{abstract}
We determined the breast-feeding patterns, Vitamin A and Iron supplement intake between various age groups of pregnant women in Adamawa state, Nigeria. Of the 161 pregnant women screened for this study, $73 \%$ were from Njoboliyo (NJ) $(n=118)$ while $27 \%$ from GD Chanrai Memorial hospital $(\mathrm{CMH})(\mathrm{n}=43)$. Of the 161 women from the two study sites, women within the 15-24 age brackets had the highest number of study participants (65) $40 \%$. Two-thirds of the study participants take supplements of Iron and Vitamin A (68\%) in both study sites, while (22\%) in Njoboliyo and (20\%) in CMH breast-feed their infants for more than 6 months. The intake of iron and vitamin A was observed to be higher in women of age 25-34, but it was statistical not significant $\left(P=0.12, D F=3, X^{2}=0.65\right)$. Comparing breast-feeding patterns irrespective of age, we observed that $94.1 \%$ of the pregnant mothers breast-feed their infants as opposed to the $5.9 \%$ that do not breast-feed, but the pattern showed no significant relationship when compared across the various age groups $\left(P=0.62, D F=3, X^{2}=3.05\right)$. We therefore recommend that proper awareness campaign and seminars be put in place by the government to help enlighten pregnant women on the need to continue breast-feeding their infants even after 6 months.
\end{abstract}

Keywords: Iron and vitamin A supplements, breast-feeding and pregnant mothers

\section{INTRODUCTION}

An overview: Nutrition is science that studies the provision to the body, of the materials that are required for the support of life. These materials are usually in the form of food. These foods contain nutrients, which are chemical substances that a living thing needs to live and grow, and survive. A balanced diet containing all necessary nutrients is the most important requirement for a healthy life. Nutrients that are needed by the body in large quantities are known as macronutrients while those that are needed by the body in relatively smaller amounts are known as micronutrients (Blake, 2008). Micronutrients function to ascertain that all the cells in our body work efficiently; examples include Vitamins, Minerals and Trace elements. Vitamins and minerals are essential for metabolism in the body. There are two kinds of vitamins namely water soluble (vitamin $\mathrm{B}_{6}$, Biotin, Thiamin, Niacin, Folate, vitamin $B_{12}$, pantothenic acid, Riboflavin and vitamin C) and fat soluble (vitamins A, $\mathrm{D}, \mathrm{E}$, and K) Calcium aids in the structure of bones and teeth while sodium helps to regulate body functions like the contractions of the heart and muscles (Harris, et al.,2006). Major minerals include calcium, chloride, magnesium, phosphorus, potassium, sodium and sulfur. There also trace minerals such as copper, chromium, fluoride, iodine, iron, selenium, manganese, molybdenum, and zinc (Harris, et al., 2006) this paper will focus on Vitamin $A$ and Iron.

Vitamin A (or retinol) is a fat-soluble organic compound. Humans are not capable of manufacturing Vitamin A themselves, and as such have to rely on other sources outside the body for its provision. It has numerous uses in the body including maintaining good vision, promoting a healthy immune system and also giving healthy strong bones. This Vitamin has both plant and animal's sources. In plants, it is found in the form of pro-vitamin A Carotenoid which is eventually converted into retinol when ingested by humans. Carotenoid are usually found in green, yellow, orange and red vegetables for example; carrots, spinach, tomatoes, mango and papaya. In animals, it is found in the form of retinol, 
which can be directly absorbed by the body. Sources include milk, eggs, chicken and cheese (Campbell, et al 2008),

Iron is an important metal for all living things. In humans, it is a component of hemoglobin, which is the protein molecule in red blood cells that carries oxygen. Other functions of hemoglobin include regulation of cell growth and differentiation, conversion of nutrients into energy and manufacture of new Deoxyribonucleic acid (DNA). Most important function however, is to transport oxygen all over the body. Iron is found in all cells in the body and is needed to synthesize Adenine Tri-Phosphate (ATP) into energy. Iron is derived from diet, from both plant and animal sources. Red meat, fish, poultry, shellfish, eggs, legumes, dried fruits and fortified cereals are sources of Iron (Harris et al., 2006). Iron can be found in the human blood and stored in the liver, spleen and bone marrow (Boyle \& Long, 2007). When iron is assimilated in the human body with other minerals, it depends on the amount of acid in the stomach. Vinegar is a good source of acid and when eaten increases the acid in the body (Boyle \& Long, 2007).

Micro-nutrients deficiency (vitamin a and iron): Even though micronutrients are needed only in small amounts, the consequences of their absence in the human body can be very severe. An unbalanced diet can have disastrous impacts on health ranging from minor effects such as tiredness and less alertness and more severe effects such as diabetes. In young children particularly, poor nutrition can affect proper growth and development. This is due to the fact that people living in developing countries have less access to a good and regular supply of food due to poverty levels, and other environmental factors such as drought and famine. Another factor that can cause this high level of micronutrient deficiency in developing countries is the lack of or inadequate health education on the benefits of eating a healthy and balanced die (Abudu, 20050. In addition to the adverse health effects posed by micronutrient deficiencies, it also has severe implications on economic development and productivity. This is particularly so with respect to the huge public health costs and loss of human capital. Along with iodine deficiency, Vitamin A and Iron deficiency together form the three most common forms of micronutrient malnutrition the world over (Allen et al, 2006).

Iron Deficiency Anemia (IDA) is the most prevalent and widespread disorder in the world today, and is also the only micronutrient deficiency that has posed a problem in industrialized countries. This disease reduces the work capacity of an individual when affected, and subsequently the entire population at large, resulting in serious economic consequences that inhibit national development (Davidson, 2011a; Davidson, 2011b). According to a nationwide food consumption and nutrition survey carried out, 34\% of children less than 5 years of age (infants), 24\% of mothers, and $48 \%$ of pregnant women have IDA in Nigeria (Millennium Development Goals, 2004). Vitamin A Deficiency Disorder (VADD) is characterized by impaired vision and it is responsible for increasing the risk of diseases and death due to severe infections. In pregnant women for instance, this deficiency causes night blindness and increases their susceptibility to mortality. It occurs mostly during the last trimester of pregnancy, when demand from the unborn child increases, and that of the mother is also at the highest level. In children, the deficiency of this Vitamin causes severe visual impairment and increases susceptibility to severe illness which in extreme cases can result to death (WHO, 2011 ${ }^{\mathrm{b}}$ ). A nationwide food consumption and nutrition survey carried out showed the percentage of VADD in Nigeria to be; $23.2 \%$ children below the age of five, $13 \%$ of mothers, and $19 \%$ of pregnant women 13 (Maziya-Dixon et al, 2006).

Cause of iron and vitamin a deficiency: In developing countries such Nigeria, occurrences of famine and drought can inhibit an individual from getting all the required nutrients necessary for growth. A deficiency can be obtainable when an individual does not take the required daily amounts of any given micronutrient. Some reasons attributed to nutrient intake failure by certain individuals could be due to gastrointestinal diseases that interfere with absorption of nutrients e.g. Crohn's disease, alcoholism and diet practices e.g. vegetarianism (Jamison et al, 2006).

The United States Institute of Medicine (IOM) and the National Academy of Sciences came up with values known as Dietary Reference Intakes (RDI's) for both Vitamins and Minerals. The RDI comprises of three sets of values which are: RDA (Recommended Dietary Allowance), Al (Adequate Intake) and The Tolerable Upper Intake level (UL). The RDA is defined as the average amount of micronutrient that is needed to meet the health needs of 97-98 percent of the population on a daily basis. The $\mathrm{Al}$ is an estimate set used when there is not enough information given to define the RDA. The UL is defined as the average of the maximum amount of 
the micronutrient that can be taken daily, without any fear of side-effects. RDAs and ULs for iron are measured in milligrams $(\mathrm{mg})$ while that of Vitamin A is measured in both micrograms and International Units (IU) (Davidson, 2001 ${ }^{\mathrm{a}}$; Davidson, 2001 ${ }^{\mathrm{b}}$ ). See table 1.1 below:

Table 1.1 Showing Recommended Dietary Allowance (RDA) for Iron and Vitamin A

RDI for Iron:

\begin{tabular}{|l|l|l|}
\hline GROUP & RDA (mg) & UL (mg) \\
\hline $\mathbf{0 - 6 m o n t h s ~}$ & 0.27 & Not established \\
\hline $\mathbf{7 - 1 2}$ months & 11.00 & Not established \\
\hline $\mathbf{1 - 3 y e a r s}$ & 7.00 & 40.00 \\
\hline 4-8years & 10.00 & 40.00 \\
\hline Pregnant women & 27.00 & 45.00 \\
\hline $\begin{array}{l}\text { Breastfeeding } \\
\text { women> 19years }\end{array}$ & 9.00 & 45.00 \\
\hline
\end{tabular}

RDI for Vitamin A:

\begin{tabular}{|l|l|l|}
\hline GROUP & RDA & UL \\
\hline 0-6months & 1330 & 2000 \\
\hline $\mathbf{7 - 1 2}$ months & 1670 & 2000 \\
\hline $\mathbf{1 - 3 y e a r s}$ & 1300 & 2000 \\
\hline $\mathbf{4 - 8 y e a r s}$ & 1330 & 3000 \\
\hline Pregnant women & 2500 & 3000 \\
\hline $\begin{array}{l}\text { Breastfeeding } \\
\text { women> 19years }\end{array}$ & 4300 & 3000 \\
\hline
\end{tabular}

\section{Supplementation and detection of vitamin a and iron}

\section{Supplements of Vitamin A And Iron:} Supplementation is a term used to describe the provision of relatively large doses of micronutrients, usually in the form of pills, capsule or syrup. It is generally made in a highly absorbable form and has the advantage of being able to supply the body with an optimal amount of a particular micronutrient. Among individuals already identified as deficient in a micronutrient, supplements have been identified as one of the fastest ways to control the deficiency. Supplementation programs have been widely used in developing countries to provide iron and folic acid in pregnant women, and Vitamin A to infants. Barriers to the success of supplementation include high expenses and lack of compliance (Allen et al, 2006).
Detection of vitamin a and iron deficiency: Symptoms of VAD include impaired vision, weakened immune system, hyperkeratosis (goose-bump like appearance on the skin) on the forearms and thighs initially, and eventually spreading all over the body and increased susceptibility to viral infections (Davidson, 2001 ${ }^{\mathrm{b}}$ ).

Symptoms of IDA include lack of energy, feelings of weakness, feeling cold frequently, increased infections, irritability, decreased performance, sore or swollen tongue and the urge to eat dirt or other nonfood substances (Davidson, 2001 ${ }^{\mathrm{a}}$ ).

Role of the nigerian government and the nongovernmental organizations: The Nigerian Government has recently embarked on a mission to stop or at least reduce micronutrient deficiency in the country. This mission includes strategies such as food fortification, micronutrient supplementation, dietary diversification, food security and nutrition education. Among all these, food fortification has been recognized as the most sustainable strategy in combating micronutrient deficiency. In a country of over 155 million people, IDA affects $69 \%$ of infants and $67 \%$ of pregnant women while VAD is found in $25 \%$ of children (Tulchinsky, 2011). In the year 2002, the Nigerian Government successfully launched its 'National Food \& Nutrition Policy' aiming to reduce malnutrition among infants. The launched campaign also concentrated on reducing iodine deficiency disorders, Vitamin A deficiency and Iron deficiency anemia by $50 \%$ before the year 2010 (Tulchinsky, 2011).

In recognizing the need for a global solution to vitamin A and iron deficiency, the World Health Organization (WHO) has lately developed an allinclusive package of public health measures which have helped to address all aspects of Iron deficiency and anemia. Such measures are currently being implemented in countries with a high level of this deficiency. Example of such measures include; the increment of iron intake by diversification of diet through food fortification, food enrichment, enhancement of iron-absorption and iron supplementation. Other measures include; the control of deadly infections e.g. malaria as well as the prevention and control of other nutritional deficiencies.

Our research therefore, aims to establish the breastfeeding patterns, Vitamin A and Iron supplement intake between various age groups of pregnant women in Adamawa state, Nigeria. In so doing, we 
can be able suggest and recommend that proper awareness campaign plus seminars be put in place by the government to help enlighten these pregnant women on the need to continue breast-feeding their infants even after 6 months.

\section{METHODS}

Study Population and Design: This is a prospective study carried out in Adamawa state, Nigeria between the periods of October to November 2011. Several short trips were made to Chanrai Memorial Hospital in Adamawa state for data collection where the medical records of the study participants were collected and stored in excel files. Within the same period, questionnaires were prepared and shared out to the pregnant women in Njoboliyo village and $G D$ Chanrai hospital (Ngurore). These questionnaires were translated in Hausa so as to enable the pregnant women provide valid information to be used for the study. The medical cards were randomly selected and mandatory ethical procedures were followed (this included obtaining the informed consent of the subjects). Some of the information obtained from the questionnaire and the medical cards included;

i. Patients' dietary patterns during pregnancy i.e. looking at their intake of vitamin $A$ and iron supplements;

ii. Records of their antenatal visits;

iii. Breast feeding patterns of the pregnant mothers:

iv. Plus other records such as age, para, gravid, abortions and infant birth weights.

Patient cards were obtained from the clinic registers $(n=118)$ and on subsequent visits to study site, four qualified nurses were brought to help dispense appropriate doses of vitamin A and iron supplements to the pregnant women and lactating mothers. Likewise, the nurses helped to given vitamin A supplements to the children below 5 years of age.

Statistical analysis: Data collected was analyzed using the data analysis feature of the Microsoft excel program. Means, median and standard deviations were computed for continuous variables. A proportional difference for trends or for any independence was tested using the chi-square (goodness of fit) test. The one-way analysis of variance (ANOVA) was used to test for differences in mean values. Statistical significance was set at $95 \%$ confidence limit and a value of $P \leq 0.05$ was used to define statistical significance.

Ethical considerations: This study undertaken was in compliance with the Declaration of Helsinki and the
International Guidelines of Biomedical Research involving human subjects. All participants in this project have read and have signed written consent forms agreeing to participate in this study. Consent from the Village Chief in Njoboliyo was obtained before the study was undertaken and also from the staff in the Antenatal clinic at GD Chanrai Memorial Hospital, Ngogure.

\section{RESULTS}

Distribution of study participants by age groups: The results of this study discovered that out of the 161 pregnant women that participated, the highest number of study participants came from women between the ages of $15-24(40 \%)$. The other age group distributions were $25-34(39 \%), 35-44(19 \%)$ and $45-54(2 \%)$.

Table 1: Distribution of study participants according to age

\begin{tabular}{|l|c|}
\hline Age Groups & No. of pregnant mothers (\%) \\
\hline $\mathbf{1 5 - 2 4}$ & $65(40)$ \\
\hline $\mathbf{2 5 - 3 4}$ & $63(39)$ \\
\hline $\mathbf{3 5 - 4 4}$ & $30(19)$ \\
\hline $\mathbf{4 5 - 5 4}$ & $3(2)$ \\
\hline Total & $161(100)$ \\
\hline
\end{tabular}

Comparing the age distribution for the two study sites, we discovered $33.1 \%$ in $\mathrm{NJ}$ and $60.5 \%$ in $\mathrm{CMH}$ for the women of 15-24 age groups. The result for the other age groups revealed; $41.5 \%$ in $\mathrm{NJ}$ versus $32.6 \%$ in $\mathrm{CMH}$ for $25-34$ age groups, $22.9 \%$ in $\mathrm{NJ}$ versus $6.9 \%$ in $\mathrm{CMH}$ for $35-44$ age groups and $2.5 \%$ in $\mathrm{NJ}$ against $0 \%$ in $\mathrm{CMH}$ for $45-54$ age bracket.

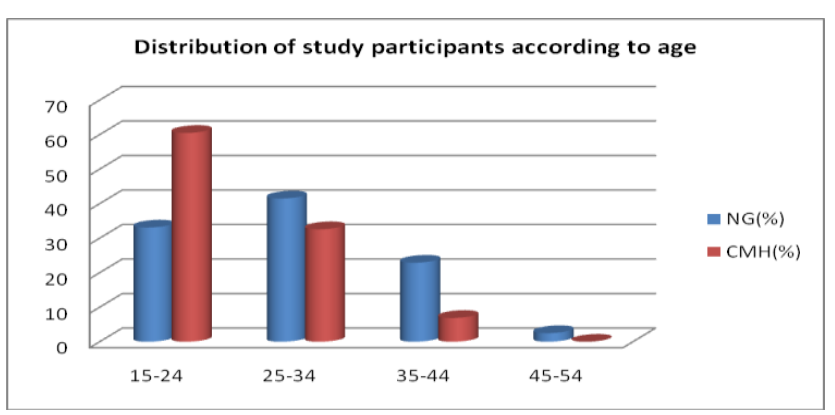

Comparing number of children between Njoboliyo women and $\mathrm{CMH}$ women

From the medical records collected, we discovered a total number of $(n=634)$ children from both Njoboliyo and $\mathrm{CMH}$ women. Our results further revealed that the women from Njoboliyo had a total number of 
( $n=488)$ children while the total number of $(n=146)$ children was counted for the women from $\mathrm{CMH}$. Looking at the number of children in the two study sites and taking number of child deliveries e.g. 1 child, 2-4 children, 5-6 children, 7 or 8 children into consideration, our results presented below showed:

Table 2. Showing the number of children in Njoboliyo village and $\mathrm{CMH}$

No. of pregnant women No. of children Per study site

\begin{tabular}{|c|c|c|c|c|c|c|}
\hline & 1 & $2-4$ & $5-6$ & 7 & 8 & Total \\
\hline $\begin{array}{l}\text { Njoboliyo } \\
(n=118)\end{array}$ & $\begin{array}{l}23 \% \\
(n=27)\end{array}$ & $\begin{array}{l}44 \% \\
(n=52)\end{array}$ & $\begin{array}{l}19 \% \\
(n=22)\end{array}$ & $\begin{array}{l}13 \% \\
(n=15)\end{array}$ & $\begin{array}{l}2 \% \\
(n=2)\end{array}$ & 488 \\
\hline $\begin{array}{l}\mathrm{CMH} \\
(\mathrm{n}=43)\end{array}$ & $\begin{array}{l}40 \% \\
(n=17)\end{array}$ & $\begin{array}{l}37 \% \\
(n=16)\end{array}$ & $\begin{array}{l}12 \% \\
(n=5)\end{array}$ & $\begin{array}{l}12 \% \\
(n=5)\end{array}$ & nil & 146 \\
\hline Total & & & & & & 634 \\
\hline
\end{tabular}

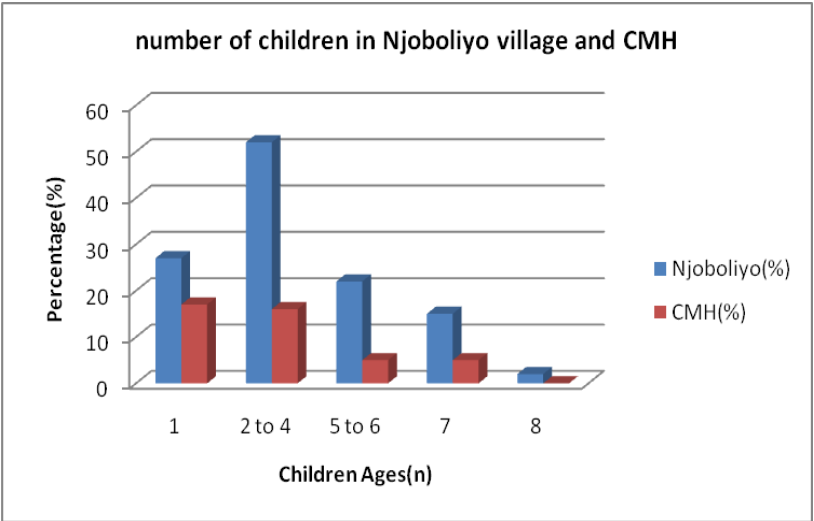

Vitamin A and Iron supplements plus breastfeeding patterns among study participants (Njoboliyo and CMH combined)

Out of the 161 women from the two study sites that participated in this study, our result showed that 80 of the women (68\%) take supplements of vitamin $A$ and iron. The intake of Vitamin A and Iron in the total study population $(n=161)$ showed that women between the ages of 25-34 consume a higher dosage of these supplements, but the result was statistically not significant $(P>0.05)$. We also found out the breast feeding pattern in the women which revealed that $22 \%$ of women from Njoboliyo and $20 \%$ from $\mathrm{CMH}$ breastfeed their infants for more than 6months. We further more made comparisons of breast-feeding patterns irrespective of age where we observed that $94.1 \%$ of the pregnant mothers breast-feed their infants as opposed to the $5.9 \%$ that do not breastfeed. This breastfeeding pattern showed no significant relationship when compared across the various age groups $\left(P=0.62, D F=3, X^{2}=3.05\right)$.

Table 3. Showing results obtained from questionnaire data of study participants

\begin{tabular}{|c|c|c|c|c|c|c|c|}
\hline 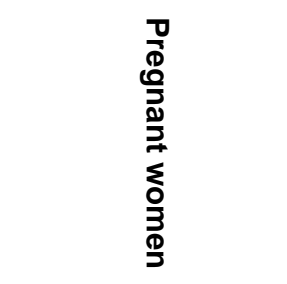 & 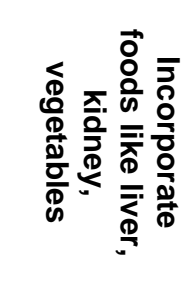 & 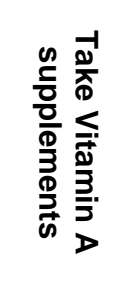 & 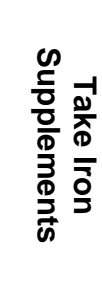 & 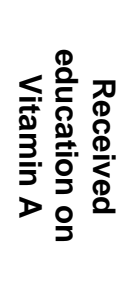 & 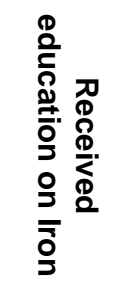 & 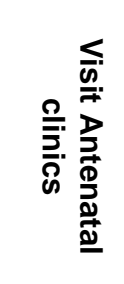 & 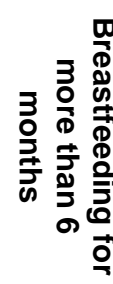 \\
\hline NJ women $(n=118)$ & $86 \%(n=101)$ & $\begin{array}{c}68 \% \\
(n=80)\end{array}$ & $\begin{array}{c}68 \% \\
(n=80)\end{array}$ & $\begin{array}{c}68 \% \\
(n=80)\end{array}$ & $\begin{array}{c}68 \% \\
(80)\end{array}$ & $\begin{array}{c}92 \% \\
(n=106)\end{array}$ & $\begin{array}{c}22 \% \\
(n=25)\end{array}$ \\
\hline $\begin{array}{l}\text { CMH } \\
(n=43)\end{array}$ & $100 \%(n=43)$ & none & $\begin{array}{l}100 \% \\
(n=43)\end{array}$ & none & $\begin{array}{c}100 \% \\
(n=43)\end{array}$ & $\begin{array}{c}100 \% \\
(n=43)\end{array}$ & $\begin{array}{l}20 \% \\
(n=6)\end{array}$ \\
\hline
\end{tabular}




\section{DISCUSSION AND CONCLUSION}

Nutritional anemia caused by vitamin A and Iron deficiency is a growing concern among pregnant women in developing countries like Nigeria. Research has shown that there is a $50 \%$ prevalence of anemia in pregnant women in Africa. (Ramakrishan, 2002). Our findings in this study showed that $68 \%$ of the pregnant women take supplements of iron. The higher prevalence $(68 \%)$ of iron supplements intake revealed in our study was similar to that observed by Scholl Theresa in 2005 who also recorded a higher prevalence of $72 \%$ iron supplements intake (Scholl, 2005)

Exclusive breastfeeding has been recommended by international agencies to mothers for the initial 6 months after birth due to its health benefits to the infants (Allen, 2005). Breast milk contains vitamin A, Iron and other nutrients needed for infant nourishment and as such, it is necessary for pregnant mothers to provide breast milk to their infants. In our study, we discovered that $94.1 \%$ of the pregnant mothers breast-feed their infants and this was similar to the $93.8 \%$ number of breastfeeding mothers (Scott et al, 2006). When we combined our result from the two study sites, we found that only $42 \%$ of the women continue with breastfeeding after 6months unlike the 53\% observed in Scott et al study in 2006.

Research has shown that the iron content in breast milk usually gets depleted in infants after their $1^{\text {st }}$ year and as such, scientist have recommended that iron supplements be given to infants even after 6 months of age (Allen, 2005)The importance of breastfeeding to infants cannot be over emphasized. Apart from its nutritional value to the infants, it also poses serious health implications if it gets depleted in body of both the mother and child. We found no recent study to support or contradict our finding in which we observed that the intake of iron and vitamin A was higher in women of age 25-34, even though it was statistical not significant.

We therefore recommend that for future research in this particular study, taking the serum levels of mother and child is required. This would help in determining the levels of micronutrient deficiency in their systems. We also recommend remedies to help eliminate the prevalence of vitamin $A$ and iron deficiencies in pregnant mothers and children. The short term remedy would be to promote exclusive infant breastfeeding by mothers and providing vitamin A supplementation to protect babies from VAD. For a long term remedy, we recommend that Vitamin A rich diets and food fortification be promoted. Finally, we recommend that proper awareness campaign and seminars be put in place by the government to help enlighten pregnant women on the need to continue breast-feeding their infants even after 6months.

Competing interests: The authors declare that they have no competing interests.

\section{ACKNOWLEDGEMENTS}

I would like to extend my sincere gratitude to Mr. Sunday Francis from the Federal University of Technology in Yola, Mr. Harrison Amos at the Ministry of Environment for Adamawa State, Mr. Nachamada Geoffrey alumni at AUN, Dr Sumit Kar and Nurse Jemima Goyol at AUN and all the staff at GD Chanrai Hospital, Ngogure; also to the Trustees of Tulsi Chanrai Foundation, to Professor Bayo Lawal and to President Margee Ensign; to the Founder of AUN, His Excellency Mr. Atiku Abubakar.

\section{REFERENCES}

Abudu, AO (2005). Eat for Health and Long Life Accra: International Millennium Ventures (GH) Limited.

Allen L, De Benoist B, Dary O \& Hurrell, R (2006). Guidelines on Food fortification with micronutrients Geneva: WHO Press. ISBN-13 9789241594011

Allen LH. (2005). Multiple Micronutrients in Pregnancy and Lactation: An Overview. American Journal of Clinical Nutrition 81:5, 12065-12125.

Bhargava A, Bouis HE, Scrimshaw NS. (2001). Dietary intakes and socioeconomic factors are associated with the hemoglobin concentration of Bangladeshi women. J Nutr.131(3):758-764.

Blake, JS. (2008). Nutrition \& You_San Francisco: Pearson Benjamin Cummings.

Boyle MA \& Long SR. (2007). Personal Nutrition, 6th Edition. Belmont: Peter Marshall Publishers.

Campbell NA, Reece JB, Mitchell LG \& Taylor MR. (2002). Biology Concepts \& Connections, $4^{\text {th }}$ edition. San Francisco: Benjamin Cummings publishers. ISBN-13 9780805366266

Darnton-Hill I, Darnton-Hill I, Nalubola R. (2002). Fortification strategies to meet micronutrient needs: successes and failures. Proc Nutr Soc. 61(2):231-41.

Harvard School of Public Health (HSPH). (2012). Vitamins. The Nutrition Source. Available from URL:

http://www.hsph.harvard.edu/nutritionsource/what-shouldyou-eat/vitamins/

Israel Olatunji Orubuloye IO \& Ishola Ajakaiye DO (2002). Health Seeking Behavior in Nigeria Ibadan: Nigerian 
Institute of Social and Economic Research. New World Press.

Jamison DT, Feachem RG, Makgoba MW, Bos ER, Baingana FK, Hoffman KJ, and Khama O Rogo KO. (2006). Disease and Mortality in Sub-Saharan Africa, 2nd edition, Washington (DC): World Bank; 2006.

Kadashi, Y. D. (2005). Vitamins and Minerals Nutritional Foods in Nigeria. Kaduna: De-Peak Publishers, Kaduna, Nigeria.

Maziya-Dixon BB, Akinyele IO, Sanusi RA, Oguntona TE, Nokoe SK, Harris EW. (2006). Vitamin A deficiency is prevalent in children less than $5 \mathrm{y}$ of age in Nigeria. $\underline{\mathrm{J}}$ Nutr. 136(8):2255-61.

Mannar MG. (2006). Successful Food-based programs, Supplementation and Fortification. J Pediatr Gastroenterol Nutr.; 43 (3):S47-53.

Millennium Development Goals Report 2004-Nigeria. Retrieved on Nov, 2011 from http://www.undg.org/archive_docs/5430-

Nigeria_MDG_Report_-_Executive_Summary.pdf

Ramakrishan Usha. (2002). Prevalence of Micronutrient Malnutrition Worldwide. Nutrition Reviews 60:5, 46-52

Scott JA, Binns CW, Oddy WH, Graham KI. (2006). Predictors of Breast Feeding Duration: Evidence from a Cohort Study. Pediatrics. 117(4) 646-655
Scholl, TO. (2005). Iron Status During Pregnancy: Setting the Stage for Mother and Infant. American Journal of Clinical Nutrition 81:5, 12185-12225.

Tish Davidson. $\left(2001^{\mathrm{a}}\right)$. Iron. Diet.com. Cited November, 2011. Available from URL: <<http://www.diet.com/store/facts/iron>

Tish Davidson. $\left(2001^{\mathrm{b}}\right)$. Vitamin A. Diet.com. Cited November, 2011. Available from URL: <http://www.diet.com/store/facts/vitamin-a>

Tulchinsky, TH (2011) Food fortification in Nigeria. The Association of Schools of Public Health in the European Region. 23 Nov, 2011. Available from URL:

$<$ http://www.blog.aspher.org/?p=65>

West KP Jr, Howard GR, Sommer A. (1989). Vitamin A and Breastfeeding: A Comparison of Data from Developed and Developing Countries. Food Nutri Bull 15, 161-77.

World Health Organization (WHO). (2011 $\left.{ }^{\mathrm{a}}\right)$. Micronutrient Deficiencies-Iron deficiency Anemia. Geneva: World Health Organization (cited November 2011). Available from URL: http://www.who.int/nutrition/topics/ida/en/index.html

World Health Organization (WHO). (2011 $\left.{ }^{\mathrm{b}}\right)$. Micronutrient Deficiencies-Vitamin A Deficiency. Geneva: World Health Organization (cited November 2011). Available from URL: http://www.who.int/nutrition/topics/vad/en/index.html 